\title{
Catalytic Enantioselective Synthesis of Adociacetylene B
}

Barry M. Trost* and Andrew H. Weiss

Department of Chemistry, Stanford University, Stanford, California 94305-8080

bmtrost@stanford.edu

\section{Supporting Information}

\section{Part B: NMR Spectra}




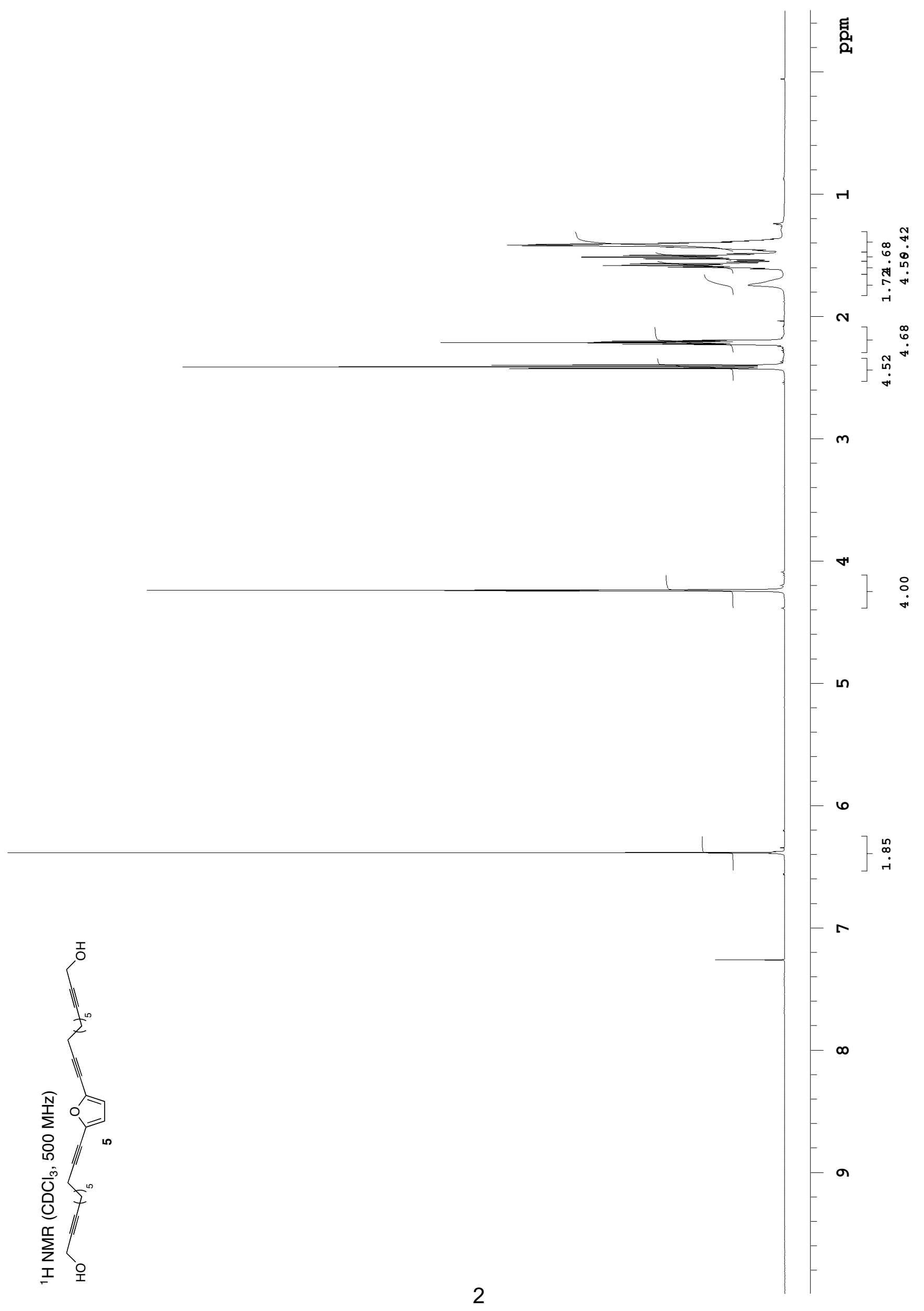




$$
1
$$




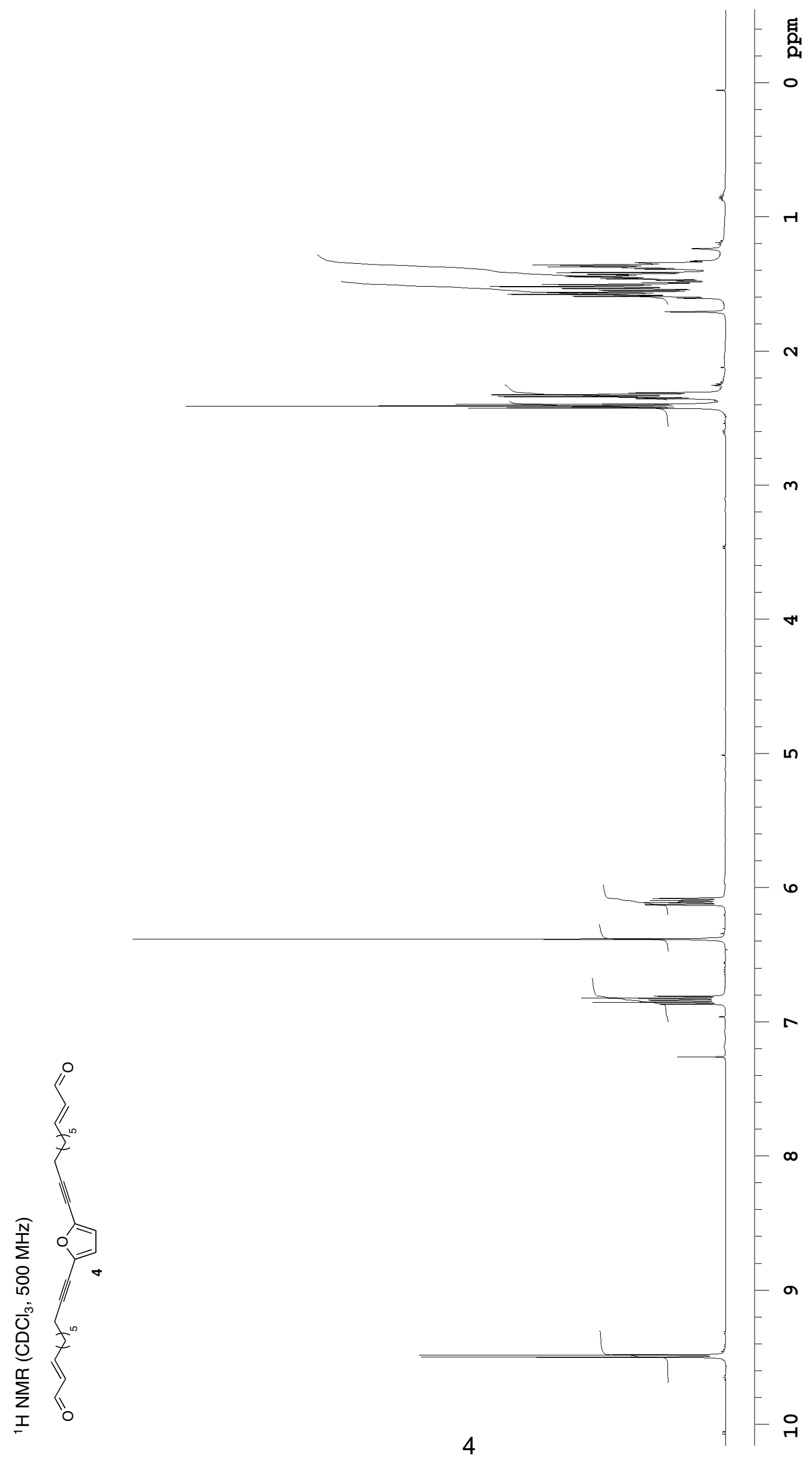




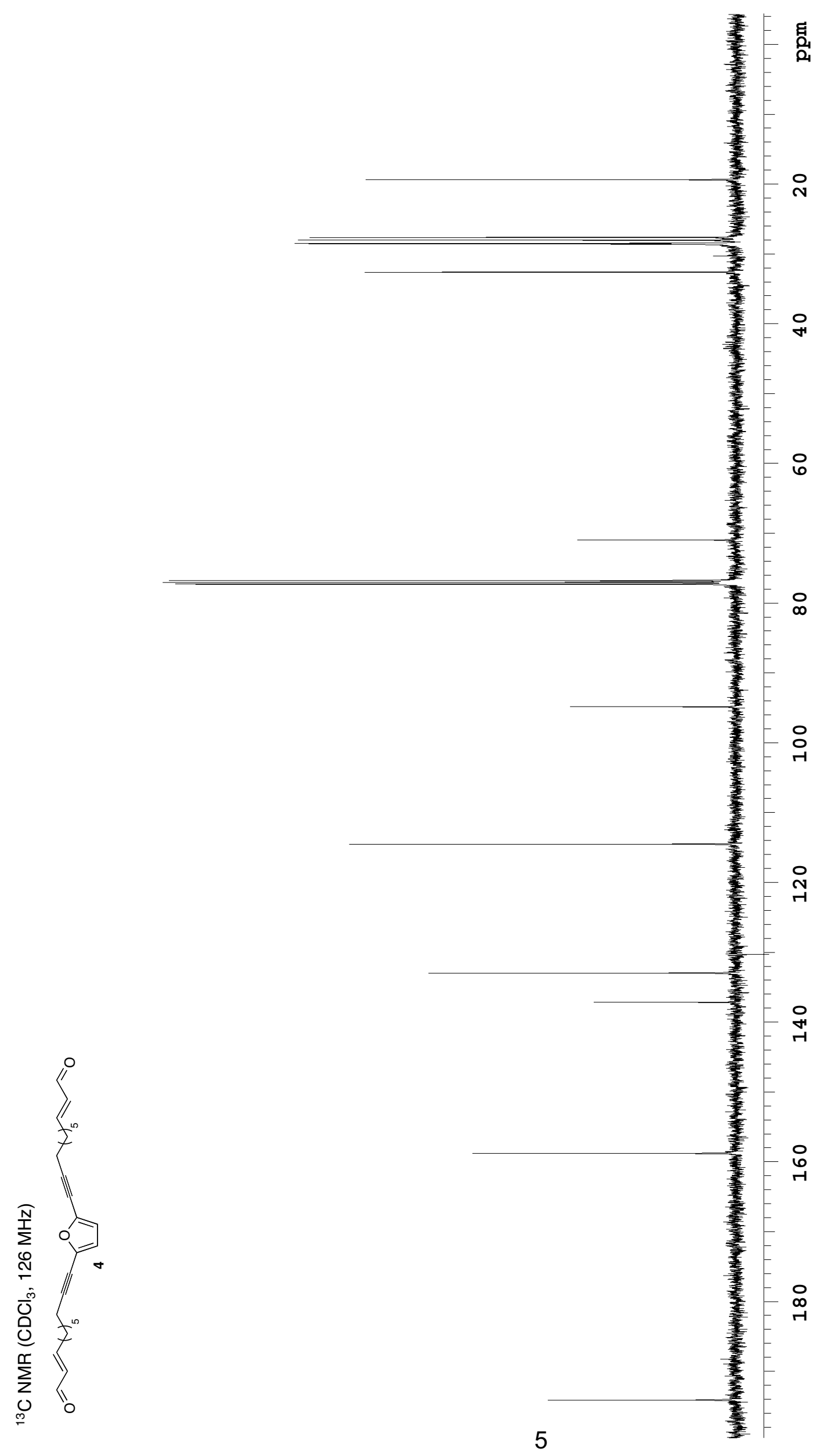




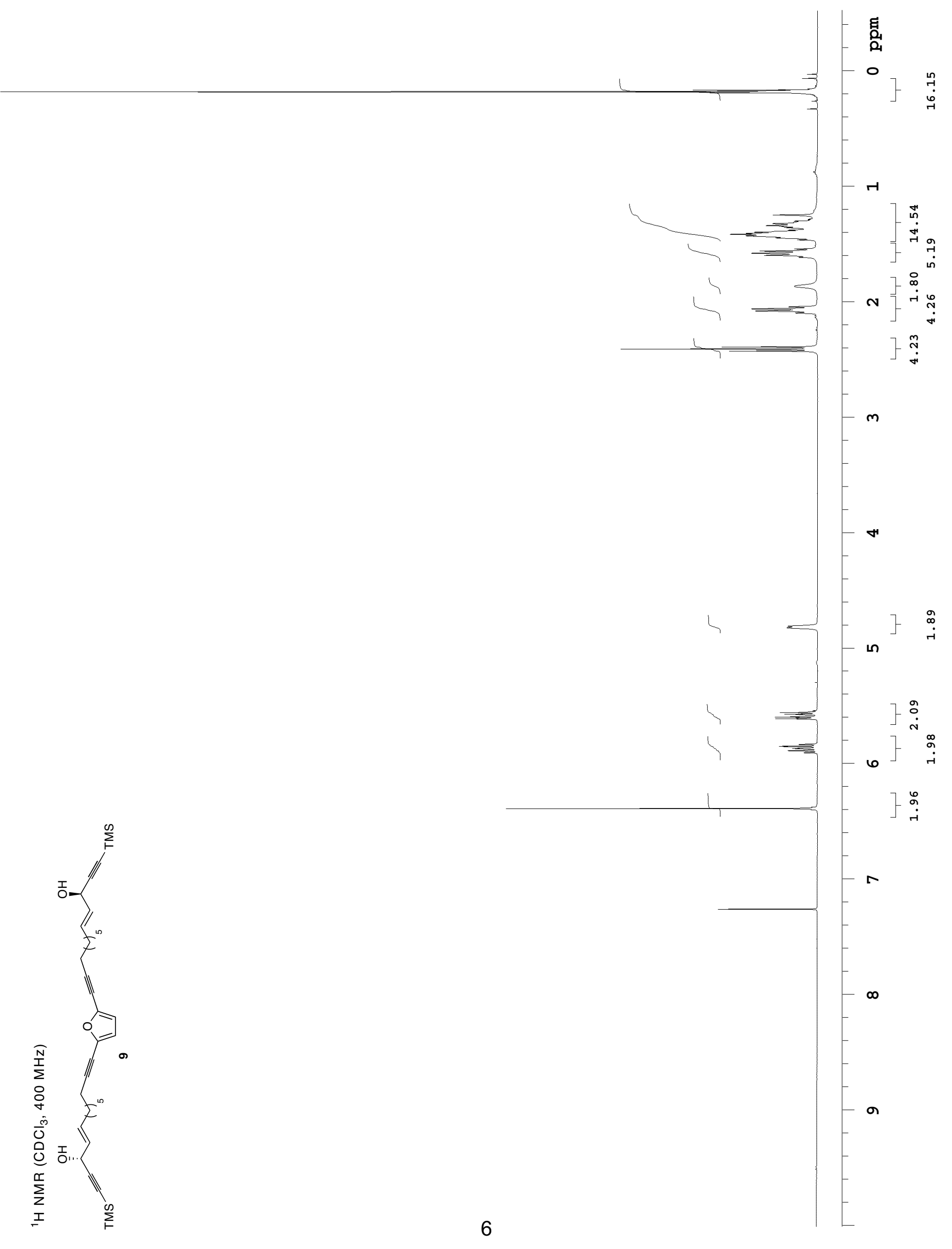




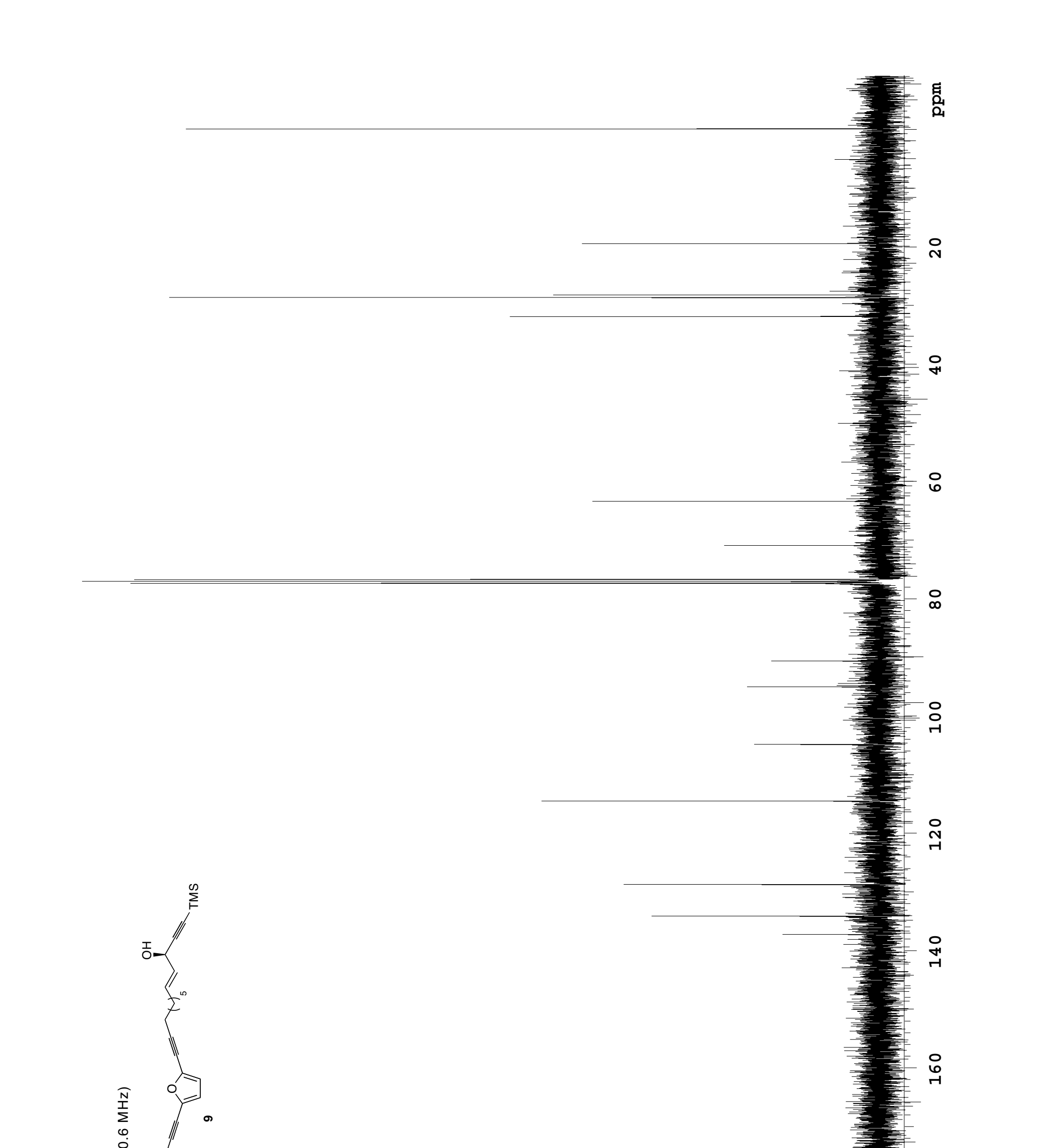




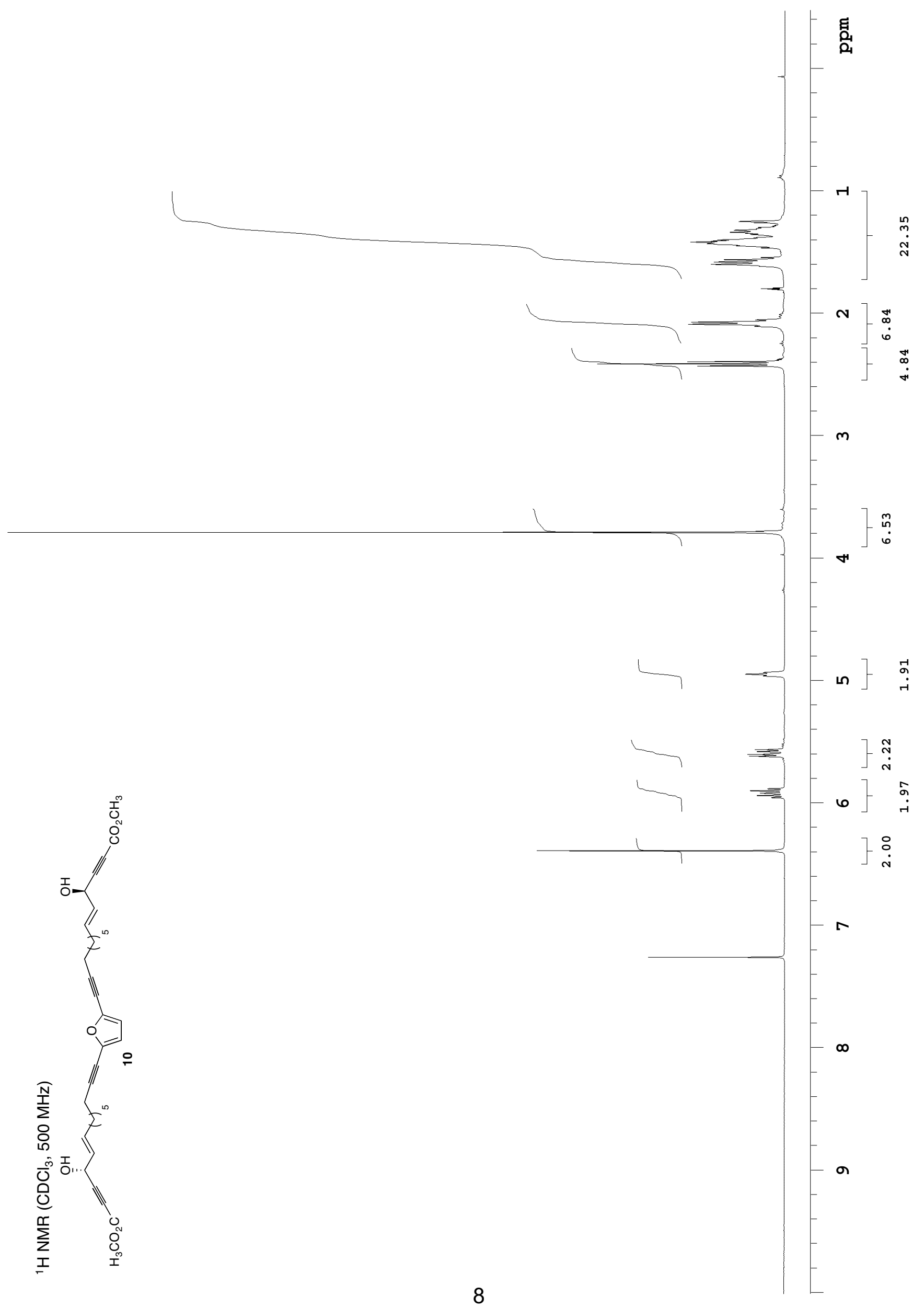





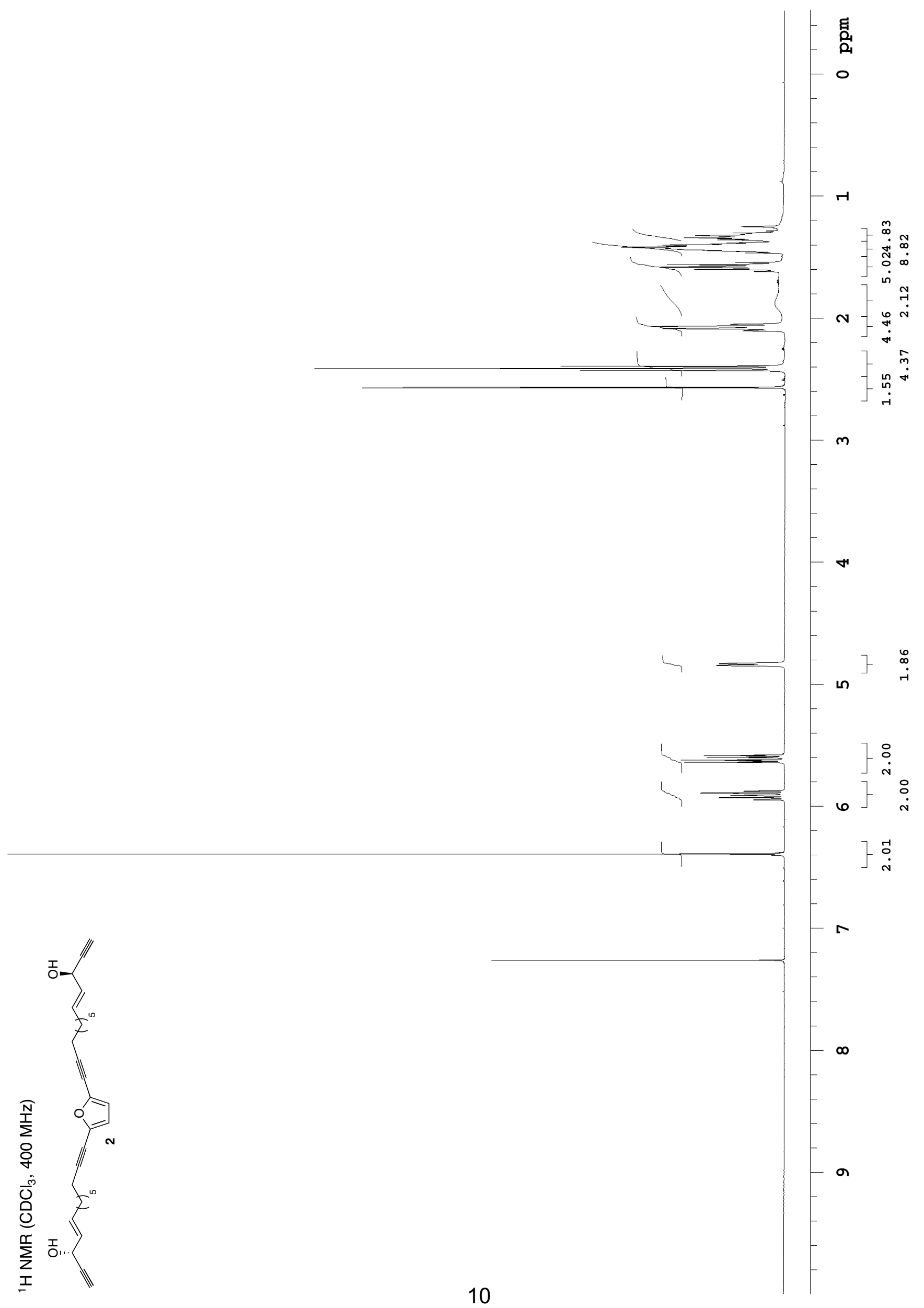




$$
\mid
$$

